\title{
A Motivação dos Profissionais de Saúde das Unidades Básicas de Saúde
}

The Health Professional's Motivation in the Basic Health Units

La Motivación de los Profesionales de Salud de las Unidades Básicas de Salud

Antônio Alves Filho

Universidade Federal do

Rio Grande do Norte

Livia de Oliveira Borges

Universidade Federal de

Minas Gerais

http://dx.doi.org/10.1590/1982 - 370001082013

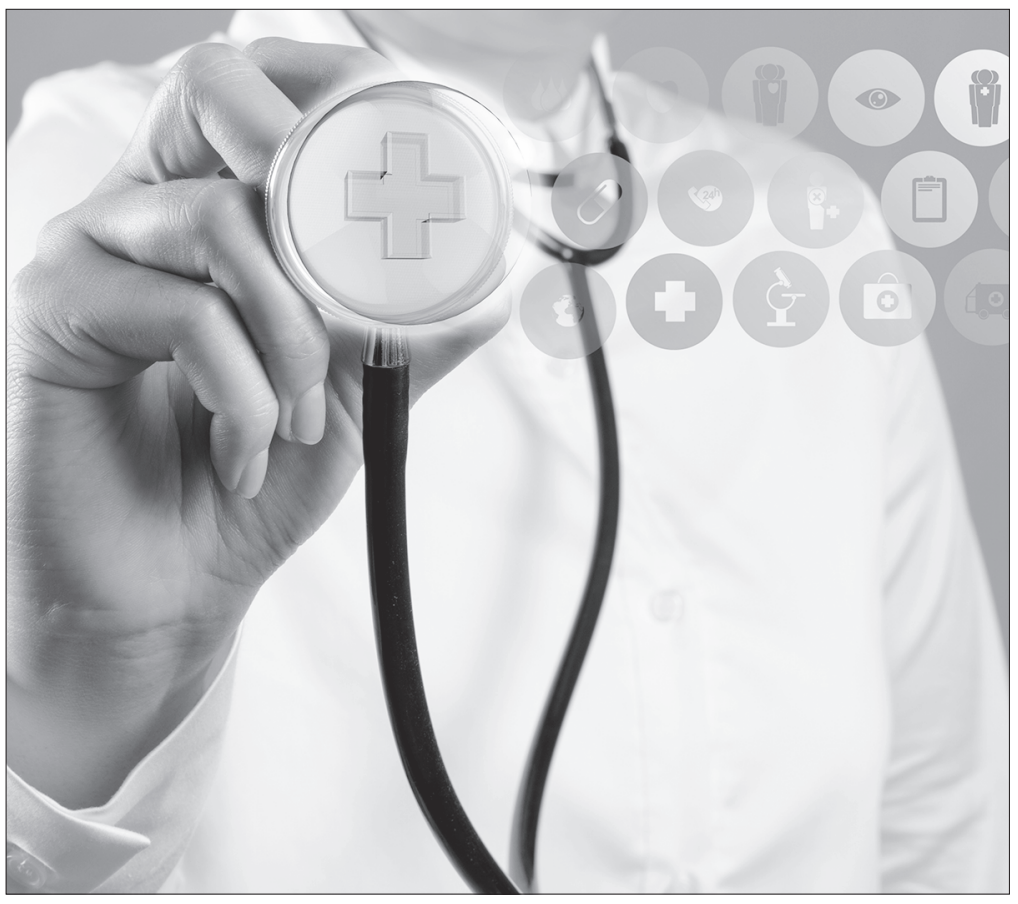


Resumo: Relata-se pesquisa que objetivou estudar a motivação para o trabalho dos profissionais de saúde vinculados às Unidades Básicas de Saúde do município de Natal. Compreendeu-se a motivação como um processo e aplicou-se a Teoria das Expectativas que a considera como um fenômeno processual e envolve cinco componentes: resultados do trabalho, expectativa, valência, instrumentalidade e força motivacional. Entendeu-se também a motivação como um fenômeno relacionado com o contexto de trabalho e adotou-se a perspectiva psicossociológica. Aplicou-se o Inventário da Motivação e Significado do Trabalho, identificando-se os fatores que mais contribuem, bem como os que enfraquecem a força motivacional dos profissionais de saúde. Conclui-se que a maioria dos profissionais apresentou força motivacional moderada e em queda, por vivenciarem e perceberem um contexto deteriorado com condições de trabalho desfavoráveis.

Palavras-chave: Motivação. Teoria da expectativa. Profissionais de saúde. Unidade básica de saúde.

Abstract: The survey that aimed at studying the health professionals' work motivation at the Basic Health Units in the Municipality of Natal is reported. Motivation was understood as a processing phenomenon involving five components: work outcomes, expectations, valence, instrumentality, and motivational power. In addition, motivation was understood as a phenomenon related to the work context and a psycho-sociological perspective was adopted. Work Motivation and Meaning Inventory was applied to identify factors that contribute most, as well as weaken, to health professionals' motivational power. One concludes that the majority of professionals presented moderate motivational power and falling, because they experience and perceive a deteriorated context with unfavorable working conditions.

Key words: motivation, expectations theory, health professionals, basic health unit.

Resumen: Se relata pesquisa que objetivó estudiar la motivación para el trabajo de los profesionales de salud vinculados a las Unidades Básicas de Salud del municipio de Natal. Se comprendió la motivación como un proceso y se aplicó la teoría de las expectativas que la considera como un fenómeno procesal e involucra cinco componentes: resultados del trabajo, expectativa, valencia, instrumentalizad y fuerza motivacional. Se entendió también la motivación como un fenómeno relacionado con el contexto de trabajo y se adoptó la perspectiva psicosociológica. Se aplicó el Inventario de la Motivación y Significado del Trabajo identificándose los factores que más contribuyen, así como los que debilitan la fuerza motivacional de los profesionales de salud. Se concluye que la mayoría de los profesionales presentó fuerza motivacional moderada y en descenso, por vivir y percibir un contexto deteriorado con condiciones de trabajo desfavorables.

Palabras clave: motivación, teoría de la expectativa, profesionales de salud, unidad básica de salud. 
As Unidades Básicas de Saúde (UBS) representam o primeiro contato de acolhimento do usuário e de formação de vínculos com as equipes de saúde, sendo local prioritário de exercício da clínica do cuidado. Compete-lhes também coordenar os fluxos das pessoas pelos serviços na rede de atenção, referendando o usuário para outros níveis de atendimento. Portanto, os profissionais de saúde das UBS estão na porta de entrada do sistema, realizando atendimentos de Atenção Básica integral à população, fazendo triagem das demandas para os outros níveis e buscando respondê-las com eficácia e qualidade. Assim, a UBS representa um lugar exigente para o profissional de saúde (Secretaria Municipal de Saúde de Natal - SMS, 2007; Botazzo, 1999).

Porém, na Secretaria Municipal de Saúde (SMS) de Natal, os desvios de função, a distribuição inadequada dos servidores, a falta de mecanismos de avaliação de desempenho, desníveis salariais, incentivos diferenciados entre as próprias unidades e a deterioração salarial do funcionalismo têm contribuído para fragilizar os compromissos profissionais, baixar o rendimento no trabalho e a motivação dos trabalhadores como um todo. Além disso, coexistem diferentes tipos de contratos empregatícios e de salários entre os que atuam nas UBS em Natal. Tais diferenças são consideradas inadequadas, causam discriminação e desestimulam o desenvolvimento do trabalho (Dimenstein \& Santos, 2005; Massud, 2001; SMS, 2003, 2009, 2010).

O quadro do Sistema de Saúde agravou-se no último governo municipal de Natal (2009-2012), que culminou com o afastamento da prefeita (http://www.tjrn.jus.br/comunicacao/noticias/1472-tj-mantem-o-afasta mento-de-micarla-de-sousa). O próprio relatório de gestão municipal de 2009, por exemplo, diz que "compromissos com a adoção de política de regulação no setor saúde ainda carecem de mecanismos como: remuneração adequada, condições de trabaIho dignas, melhor estruturação de vínculos contratuais e de carreira no SUS, dentre outras questões" (SMS, 2009, p. 34). O relatório de 2010 repete o mesmo texto, revelando a estagnação da situação.

Frequentemente, veículos de comunicação têm denunciado descasos dos governos federal, estadual e municipal com relação ao setor saúde, revelando ser um problema em todos os níveis de gestão. Em Natal, boletins informativos do Sindicato dos Trabalhadores em Saúde (Sindsaúde) abordam a precarização no setor, expondo um contexto de ineficiência gerencial pela falta de profissionais de saúde, insumos, equipamentos e política salarial adequada. Greves têm ocorrido em função de desajuste salarial e condições precárias de trabalho, mas poucas soluções se concretizaram. Um ponto recorrente nos referidos boletins tem sido o Plano de Carreira, Cargos e Vencimentos (PCCV). Apesar de há muito tempo reivindicado pelos trabalhadores da saúde, somente em 2011 foi implementado, porém não como esperado, continuando como fonte de insatisfação.

Nas negociações entre os governos estaduais, municipais, sindicatos e representantes das secretarias de saúde, as pautas levam ao debate necessidades da realização de concurso público; a valorização do trabalhador de saúde; a melhoria das condições de trabalho; o reajuste salarial; a informatização de cadastros; a necessidade da contratação de pessoal para a Atenção Básica e a racionalização de gastos, porém sem muito sucesso. Nas negociações, as ameaças parecem imperar, segundo os boletins do Sindsaúde (http://www.sindsaudern.org.br/site2012/down loads.php?pagina =1).

Em uma audiência pública realizada em abril de 2013 pela Câmara Municipal de Natal 
para discutir a gestão da saúde pública, conforme registro do Jornal de Hoje (http://jornaldehoje.com.br/camara-municipal-de-natal-discute-problemas-da-saude-publica-eprivada/), o atual secretário de Saúde de Natal declarou que sua gestão tem como objetivo reconstruir o Sistema Único da Saúde (SUS); destacou os descasos, descontinuidade administrativa e descompromisso, além da ingerência política, baixa qualificação da gestão e a tentativa de privatização da gestão da saúde; assinalou a carência de recursos humanos, problemas de gestão, a desmotivação profissional com baixos salários, desmoralização e desrespeito aos servidores, a judicialização da saúde e o engessamento burocrático.

Na referida audiência pública, o presidente do Sindicato dos Médicos pontuou a degradação da assistência à saúde no estado, revelando que o sindicato possui um diagnóstico indicando que a defasagem da rede de saúde ocorre há mais de 20 anos. Um médico e ex-diretor de um grande hospital geral público afirmou que a reestruturação da rede básica de saúde é requisito para fazer frente ao atendimento dos pacientes com demandas de baixa complexidade e para que os hospitais possam cumprir o papel previsto no SUS.

Os exemplos citados do que pensam os atores socioinstitucionais envolvidos com a assistência à saúde servem para indicar que os problemas são de longa data, atravessam gestões e se agravam. Compete, então, indagar: Como ficam os trabalhadores da saúde? E a motivação para o trabalho? Tal contexto provavelmente influencia a percepção dos profissionais de saúde quando avaliam o setor e minimiza a crença no potencial dos seus esforços à condução dos resultados esperados. Essas considerações sustentam a hipótese da instalação de um processo de desmotivação para o trabalho. Justificam, por consequência, realizar pesquisa sobre a motivação ao trabalho dos profissionais de saúde das UBS de Natal, partindo-se da concepção da motivação como um processo resultante da interação entre aspectos individuais e ambientais (Latham \& Pinder, 2005).

Além da relevância da pesquisa assentada no contexto socioinstitucional, considera-se também que, segundo a literatura especializada (Antoni, 2004; Fernet, 2013; Houkes, Janssen, Jonge, \& Nijhuis, 2001; Latham \& Pinder, 2005; Salanova, Hontangas, \& Peiró, 2002; Smrt \& Karau, 2011; Tamayo \& Paschoal, 2003) segue sendo preocupação das organizações e de pesquisadores a motivação das pessoas em relação ao seu trabalho.

\section{Quadro teórico: a Teoria das Expectativas}

Para este artigo, o foco de atenção será a Teoria das Expectativas, cujos conceitos fundamentaram as opções metodológicas, as análises e discussões dos resultados. Tal teoria é também conhecida como Teoria da Expectância (Latham \& Pinder, 2005) e, realmente, o próprio Vroom (1964) designa um dos componentes da teoria como expectancy e não de expectatives, porém ele não justifica a razão da diferenciação terminológica. Segundo Locke e Latham (1990), Vroom (1964) introduziu o conceito de expectativas à reflexão sobre a motivação.

Muchinsky (1994) caracteriza a Teoria das Expectativas como cognitiva, pois compreende que cada pessoa toma a decisão de dedicar esforços às tarefas para obter as recompensas desejadas e/ou atingir os objetivos esperados. Segundo Francès (1995), centra a atenção sobre o processo da motivação e não exatamente ao seu conteúdo. Pressupõe a unidade entre a mente e a ação humana e valoriza a volição. Assim, parte da crença de que as pessoas sabem o que querem do seu trabalho e compreendem que o desempenho contribui 
para o alcance dos resultados desejados (Francès, 1995; Klein, 1990; Muchinsky, 1994; Vroom, 1964). Tal teoria, operacionalmente, centra-se nos processos cognitivos desenvolvidos pelas pessoas em referência aos resultados do trabalho. Estes são as consequências da atividade de trabalho, tais como salário, promoções, bem-estar e férias. Podem se referir a aspectos simbólicos como realização, reconhecimento, valorização, contribuição social, gosto pelo que se faz, dentre outros. Também abrangem consequências indesejadas ou repulsivas, como desgaste físico, sofrimento psíquico e discriminação. Os resultados, portanto, não são necessariamente previstos pela organização do trabalho. O potencial motivador dos resultados do trabalho estaria nos sentidos simbólicos construídos pelas pessoas em referência a eles. Vroom (1964) operacionalizou tais sentidos nos seguintes conceitos e/ou processos:

- Valência: é a orientação acerca dos resultados que se definem em termos de atração ou de satisfação antecipada. Os empregados nas vivências no trabalho representam cada resultado esperado, com valências que podem ser positivas ou negativas.

- Instrumentalidade: é o grau percebido de relação entre a execução das tarefas e a obtenção dos resultados. Significa quanto a consecução de um resultado é percebida pelo sujeito em uma condição de dependência do seu trabalho. É a medida das contribuições do sujeito para a consecução dos objetivos e/ou geração dos resultados esperados.

- Expectativa: é a avaliação subjetiva da probabilidade de ocorrência do resultado esperado.

A partir desses três conceitos, Vroom (1964) formulou o de força motivacional como a quantidade de esforço ou pressão de uma pessoa para agir ou desempenhar um trabaIho. É o produto da valência pelo valor ins- trumental e pela expectativa, expresso na seguinte fórmula: $\mathrm{FM}=\mathrm{E}$ [S Vi li], onde: $\mathrm{FM}=$ força motivacional; $\mathrm{E}=$ expectativa; $\mathrm{V}=$ valência; e I= instrumentalidade.

A Teoria das Expectativas gerou controvérsias no campo da Psicologia do Trabalho e das Organizações. Assim, Korman, Greenhaus e Badin (1977) negaram seu amparo empírico, enquanto outros o afirmaram (Alves Filho \& Araújo, 2001; Antoni, 2004; Borges \& Alves-Filho, 2001, 2003; Carvalho \& Souza, 2007; Erez \& Isen, 2002; Hertel, Konradt, \& Orlikowsky, 2004; Klein, 1990; Klein, Wesson, Hollenbeck, \& Alge, 1999; Muchinsky, 1994; Régis \& Calado, 2001).

Locke e Latham (2002) consideraram que a Goal Setting Theory é mais apropriada para abordar o processo motivacional e contradiz a Teoria da Expectância. Latham e Pinder (2005), apesar de declararem que poucos modelos novos de motivação impactaram tanto quanto as teorias das necessidades de Maslow, do estabelecimento de metas de Locke e Latham e a das expectativas de Vroom, afirmam também que a Teoria das Expectativas foi superada pelas noções de goal-setting e pelas teorias da cognição social. Entretanto, a literatura (Borges, Tamayo, \& Alves-Filho 2008; Hammond et al., 2011; Hertel, Konrad, \& Orlikowski, 2004; Klein, 1990; Smrt \& Karau, 2011) tem ratificado que ela segue em voga e que sua aplicação nas pesquisas tem avançado. Clareiam os conceitos centrais da teoria - valência, instrumentalidade e expectativas (VIE) como aspectos simbólicos socialmente construídos, no nível individual de análise, mas concebendo o sujeito em interação e ativo em relação ao ambiente em que se insere. Assim, há publicações (Hammond et al., 2011; Hertel, Konrad, \& Orlikowski, 2004; Klein, 1990; Smrt \& Karau, 2011) que inseriram tais conceitos no contexto 
de modelos teóricos multiníveis, aplicando-os para apreender o processo psicológico no nível individual de análise.

Tais publicações tenderam a articular diferentes teorias consolidadas na literatura. Assim, Hertel et al. (2004) propôs um modelo multinível em que incluíram a noção de goalsetting entre os conceitos que visam a apreender o contexto e, no nível individual, articularam os conceitos de autoeficácia e de confiança no grupo aos de valência e instrumentalidade. No lugar de rejeitar a Teoria das Expectativas, indicaram que seus conceitos são parciais, exigindo complementariedade com os de outras teorias. Os modelos propostos nessas publicações e em outras (Kanfer \& Ackerman, 1989) adotaram, portanto, uma abordagem multidimensional do processo psicológico e multinível na sua explicação, identificando e classificando antecedentes e explorando suas relações com os componentes motivacionais.

Vários autores (De Deu, Nijstad, Bechtold, \& Baas, 2011; Hertel et al., 2004, Johnson \& Wallace, 2011; Pearsall, Christian, \& Ellis 2010; Smrt \& Karau, 2011) abordaram o processo motivacional em nível de análise predominantemente grupal e interacionista. Objetivaram explicar o desempenho de grupos e a implicação de cada um na atuação grupal. Portanto, é marcante a tendência à consistência para com a definição, já citada, de Latham e Pinder (2005) do processo motivacional envolvendo aspectos individuais e ambientais. Os autores (Kanfer \& Ackerman, 1989) têm pesquisado sobre traços de personalidade implicados no processo motivacional, considerando-os como componentes de um processo mais amplo, que pressupõe um sujeito inserido no contexto sócio-organizacional. Portanto, há a tendência de compreender a motivação ao trabalho no contexto teórico de perspectivas de análises interacionistas.
Também há quem aponte para a importância de compreender o processo motivacional considerando suas articulações com fenômenos macrossociais (Baum \& Locke, 2004). Levando a cabo essa tendência, pesquisas abordaram o processo motivacional no contexto cultural, por exemplo: Hangström e Gramerale (1995) relacionaram o processo motivacional às orientações materialistas e pós-materialistas de valores; Tamayo e Paschoal (2003) discutiram o fundamento dos motivos para ação a partir da tipologia dos valores humanos; Borges, Tamayo e AlvesFilho (2005) mostraram a variância da força motivacional segundo os clusters de significado do trabalho identificados entre profissionais de saúde; Smrt et al. (2011) mostraram a moderação da adesão à ética protestante do trabalho na motivação para o trabalho em equipes; Johnson e Wallace (2011) focalizaram entre antecedentes da motivação a influência das lideranças, o ambiente organizacional e o contexto cultural; Latham e Pinder (2005) argumentaram que há avanços na compreensão da influência das culturas nacionais na motivação, bem como que os valores são as raízes das necessidades humanas, a principal fonte para as metas motivacionais (goals) e para a construção das expectativas e valência dos resultados esperados. Tal interpretação dos conceitos de expectativa e valência ratificou o fato de Vroom (1964) incluir, na definição de valência, a expressão das preferências dos indivíduos e designar as expectativas de crenças.

Adicionalmente, registramos que Fernet (2013) sublinhou a importância de compreender o dinamismo do processo motivacional em uma perspectiva temporal. E Kolman et al. (2012) desenvolveram, a partir de análise semiótica das publicações sobre motivação, uma classificação das diferentes teorias segundo seus pressupostos. A um dos seus clusters designaram de pressupostos humanistas, descrevendo-os como aqueles centrados nos interesses humanos ou valores, nas 
crenças humanas, nas singularidades pessoais, na atribuição de importância ao crescimento humano em área como o amor, a realização, a autoestima e a autonomia. Kolman et al., entretanto, não situaram a Teoria das Expectativas nesse conjunto de pressupostos, o que aqui se propõe haja vista as considerações anteriores. É pertinente considerar os conceitos da Teoria das Expectativas no contexto das abordagens da motivação designadas por Nuttin (1980/1983) como interacionistas, que concebem o ser humano relacional e cujas preferências são construídas em sua inserção social. Para o autor, a motivação deve ser compreendida no contexto dos projetos de vida das pessoas e nas estruturas que conectam meios e fins (Nuttin, 1980/1983; Sampaio, 2010). Compreende-se que os conceitos (VIE) da Teoria das Expectativas puseram em conexão as ações das pessoas e os resultados esperados e/ou suas metas. Essa forma de conceber a motivação é concernente com as abordagens psicossociológicas que tendem a considerar os fenômenos como multidimensionais, multiníveis, dinâmicos e cujos sentidos se revelam e se constroem nas experiências de vida situadas no contexto sócio-histórico e temporal.

Vroom (1964) desenvolveu seu modelo de motivação considerando quatro grupos de resultados esperados do trabalho: 1) provisão de salário; 2) o dispêndio de energia física e mental; 3) a produção de bens e senviços; e, 4) as interações sociais com outras pessoas e status social. A classificação de resultados esperados de Vroom diz respeito a onde e quando desenvolveu seu modelo nos Estados Unidos; realidade diferenciada daquela em que a presente pesquisa se desenvolveu. Por isso, buscaram-se critérios baseados na realidade local para definir conjuntos de resultados a serem considerados.

Os estudos desenvolvidos por Borges e Alves Filho (2001, 2003) consistiram na elaboração e avaliação das qualidades psicométricas do Inventário da Motivação e do Significado do Trabalho (IMST) para bancários e profissionais de saúde. Para selecionar os resultados aos quais as pessoas atribuem expectativas e instrumentalidade, partiram de estudos sobre significado do trabalho e elucidaram uma estrutura fatorial segundo a qual os participantes da pesquisa organizaram aquelas atribuições. Os fatores identificados e relacionados a dois componentes conceituais do Modelo das Expectativas (expectativa e instrumentalidade) estão sintetizados na Tabela 1.

Tabela 1. Fatores identificados em expectativa e instrumentalidade

Fatores de expectativa

Justiça no Trabalho

Autoexpressão e Realização

Pessoal

Sobrevivência Pessoal e

Familiar

Responsabilidade

\section{Conceitos}

define que o ambiente de trabalho deveria garantir as condições materiais, de assistência, de higiene e de equipamentos adequados às características das atividades e à adoção das medidas de segurança, garantir o retorno econômico compatível, o equilíbrio de esforços e direitos entre os profissionais, o cumprimento das obrigações pela organização.

o trabalho deveria oportunizar expressão da criatividade, da aprendizagem contínua, capacidade de tomar decisões, sentimento de produtividade, das habilidades interpessoais, e do prazer pela realização das tarefas.

o trabalho deveria garantir as condições econômicas de sobrevivência, de sustento pessoal e de assistência à família, a existência humana, a estabilidade no emprego, o salário e o progresso social.

o quanto o indivíduo espera ser responsável pelo que faz, assumindo suas ocupações, suas obrigações e respeitando a hierarquia. 


\section{Fatores de instrumentalidade}

Envolvimento

Justiça no Trabalho

Desgaste e Desumanização

Reconhecimento e

Independência Econômica

\section{Conceitos}

indica quanto os indivíduos percebem a importância do desempenho para resolverem problemas, serem responsáveis pelas decisões, sentirem-se dignos, adaptados às normas, respeitadores da hierarquia, identificados com as tarefas, merecedores de confiança, incluídos no grupo e serem produtivos e eficientes.

o quanto percebem a utilidade do desempenho para obterem equipamentos adequados, conforto, igualdade de direitos, assistência, salário suficiente e proporcionalidade entre esforços e recompensas.

o quanto percebem o desempenho como responsável por provocar esforço físico, atarefamento e pressa, por submetê-los à discriminação, por sentirem-se esgotados e como máquina ou um animal.

o quanto percebem a utilidade do desempenho para obtenção de reconhecimento, de consideração pelas suas opiniões, de oportunidade de profissionalização e de independência econômica e de garantia do sustento.

\section{Método}

A pesquisa de campo foi desenvolvida, em uma perspectiva amostral, com aplicação de um questionário estruturado, guiando-se pelos seguintes objetivos específicos: 1) apresentar quais as expectativas e instrumentalidades atribuídas pelos profissionais de saúde das UBS ao trabalho que desenvolvem nessas Unidades; e, 2) caracterizar a força motivacional desses profissionais; 3) comparar os resultados encontrados no atual estudo, com dois outros antecedentes. $\mathrm{O}$ terceiro objetivo implica a adoção de um design transversal do tempo.

\section{Participantes}

A população do presente estudo foram os profissionais de saúde vinculados às 60 UBS do município de Natal que se distribuem em cinco distritos (14 no Distrito Norte I, 13 no Distrito Norte II, 8 no Distrito Sul, 11 no Distrito Leste e 14 no Distrito Oeste). A aplicação foi por acessibilidade, em 26 UBS e nos 5 distritos, compondo uma amostra do tipo acidental. Ao término, foram contabilizados 362 questionários válidos. Feita a tabulação dos dados, levantou-se a frequência por ocupação ou profissão, se considerando apenas aquelas com mais de 20 participantes. A amostra final ficou composta por 218 profissionais (Tabela 2).

Tabela 2. Percentual da Amostra por Ocupação $(n=218)$

\begin{tabular}{lcc}
\hline \multicolumn{1}{c}{ Ocupação } & Frequência & Porcentagem \\
\hline Agente Comunitário de Saúde-ACS & 76 & 34,9 \\
Auxiliar de Consultório Dentário-ACD & 20 & 9,2 \\
Dentista & 29 & 13,3 \\
Enfermeiro & 32 & 14,7 \\
Médico & 24 & 11,0 \\
Técnico em Enfermagem & 37 & 17,0 \\
Total & 218 & 100,0 \\
\hline
\end{tabular}


Desse total, 52 profissionais eram do Distrito Norte I, 52 do Norte II, 39 do Sul, 27 do Leste e 48 do Oeste. A maioria é casada (55\%), do sexo feminino (86,2\%), tem filhos (76,6\%) e idades variando de 23 a 63 anos $(M=42,79 ; D P=9,02)$. Em relação à escolaridade, 47,7\% completaram o ensino médio e 47,3 \% possuem nível superior. O tempo mínimo de serviço na instituição é de um ano e o tempo máximo 36 anos ( $M=13,50$; DP = 8,30).

\section{Instrumentos de coleta de dados}

Aplicaram-se uma ficha sociodemográfica e parte do IMST. A primeira serviu para caracterizar a amostra. Do IMST, utilizaram-se as questões referentes às expectativas e instrumentalidades. O IMST conta com três pesquisas (Borges \& Alves-Filho, 2001, 2003; Borges et al., 2008) que promoveram seu gradual aperfeiçoamento e puseram em teste sua validade de construto, consistência e estrutura fatorial (Tabela 3). O IMST não mensura diretamente a valência, mas a deduz da distribuição das respostas aos itens dos atributos valorativos - componentes do significado do trabalho em que os participantes definem o que deveria ser (Borges et al., 2008). Toma-se, então, alguns fatores como de valência positiva (+1) e outros, negativa (-1).

Tabela 3. Estrutura Fatorial de Instrumentalidade e Expectativa

\begin{tabular}{|c|c|c|c|c|c|}
\hline Fatores de Intrumentalidade & PEV* & $\alpha^{* *}$ & Fatores de Expectativas & PEV* & $\alpha$ \\
\hline Envolvimento & 0,23 & 0,88 & Autoexpressão e Justiça no Trabalho & 0,28 & 0,94 \\
\hline Justiça no Trabalho & 0,09 & 0,89 & Segurança e Dignidade & 0,08 & 0,71 \\
\hline Desgaste e Desumanização & 0,05 & 0,72 & Desgaste e Desumanização & 0,04 & 0,83 \\
\hline \multicolumn{6}{|l|}{ Reconhecimento e } \\
\hline Independência Econômica & 0,04 & 0,81 & Responsabilidade & 0,04 & 0,66 \\
\hline
\end{tabular}

Legenda: *PEV (Proporção de explicação da variância); ${ }^{* *} \alpha$ (Coeficiente Alfa de Cronbach)

Estimou-se a força motivacional pelo produto dos somatórios dos escores nos fatores de expectativas e o somatório dos escores nos fatores de instrumentalidade, subtraído o produto dos escores no fator de expectativa e de instrumentalidade referidos a resultados indesejáveis (ou não atrativos) do trabalho, ou seja, para os resultados os quais, por hipótese, atribui-se valência negativa (Borges et al., 2008).

\section{Procedimentos de coleta e análise de dados}

Realizou-se a pesquisa mediante solicitação da SMS de Natal e negociou-se a aplicação dos questionários em reuniões com os diretores dos cinco distritos e com os gerentes das UBS, nas quais se definia um calendário de campo. A aplicação foi realizada individualmente e, algumas vezes, em grupo de 5 a 10 profissionais, respeitando a dinâmica do trabalho.

Para caracterização da amostra, aplicaram-se estatísticas descritivas (média, desvio-padrão e frequência). Para a consecução dos objetivos de pesquisa, aplicaram-se análises descritivas e inferenciais que serão detalhados à proporção que se relatarem os resultados.

\section{Resultados}

Para a consecução do primeiro objetivo específico, estimaram-se os escores nos fatores de expectativa e de instrumentalidade, levantando-se as médias e os desvios-padrão da amostra em 
cada fator, bem como a frequência de participantes por intervalos da distribuição de escores (0 a 4). Sobre os fatores de expectativa (Tabela 4), os profissionais de saúde, em três deles - (FE1) Autoexpressão e Justiça no Trabalho, (FE2) Segurança e Dignidade e (FE4) Responsabilidade, concentram-se no intervalo no qual os escores são maiores que 3 (escala de 0 a 4). É nesses fatores que os desvios-padrão são menores. No outro fator, (FE3) Desgaste e Desumanização, as respostas mostram-se mais dispersas.

Tabela 4. Escores dos participantes nos fatores de expectativa $(n=218)$

\begin{tabular}{|c|c|c|c|c|c|c|}
\hline \multirow{2}{*}{ Fatores } & \multirow{2}{*}{ Média } & \multirow{2}{*}{$\begin{array}{l}\text { Desvio- } \\
\text { padrão }\end{array}$} & \multicolumn{4}{|c|}{ Frequência de participantes por intervalos } \\
\hline & & & $x \leq 1$ & $1<x \leq 2$ & $2<x \leq 3$ & $x>3$ \\
\hline FE1 - Autoexpressão e Justiça no Trabalho & 3,52 & 0,57 & 0,0 & 3,2 & 13,3 & $\mathbf{8 3 , 5}$ \\
\hline FE2 - Segurança e Dignidade & 3,50 & 0,67 & 0,0 & 5,0 & 12,4 & 82,5 \\
\hline FE3 - Desgaste e Desumanização & 2,10 & 0,81 & 8,7 & 35,3 & 42,7 & 13,3 \\
\hline FE4 - Responsabilidade & 3,34 & 0,69 & 0,5 & 4,6 & 17,0 & 78,0 \\
\hline ANOVA & & $\mathrm{F}=$ & 145,64 par & $p<0,001$ & & \\
\hline
\end{tabular}

Observa-se também, na Tabela 4, que os profissionais de saúde apresentaram médias com magnitudes diferentes entre os fatores, o que é corroborado pela ANOVA ( $F=145,64$ para $p<$ 0,001). O teste post hoc (Bonferroni) revelou três níveis distintos de expectativas, conforme se pode visualizar na Figura 1. O mais esperado pelos profissionais de saúde no seu trabalho são oportunidades de sentir reconhecimento, expressar criatividade, influenciar nas decisões e obter justiça no trabalho. Igualmente, esperam segurança e dignidade. Com menos intensidade, esperam responsabilidade e, menos ainda, desgaste e desumanização.

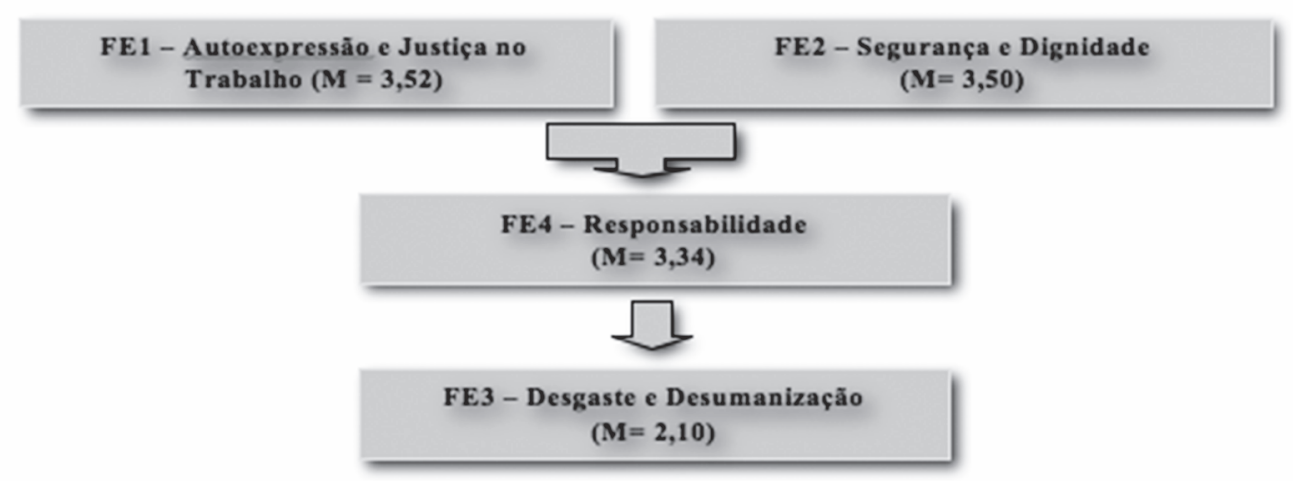

Figura1. Níveis Identificados nos Fatores de Expectativa

Com relação à instrumentalidade, na Tabela 5, constatou-se apenas no fator (Fl1) Envolvimento, maior concentração dos profissionais no intervalo de escores maiores que 3. Nos demais fatores, ocorreu maior dispersão, porém com concentrações elevadas no intervalo moderado superior (2<x 3). No fator (FI3) Desgaste e Desumanização, há uma frequência considerável no intervalo moderado superior, bem como o maior desvio-padrão. Neste fator, a soma das frequências dos intervalos moderado superior e superior indica que, apesar de pouco esperado, os profissionais de saúde percebem o trabalho como responsável por sua obtenção. 
Tabela 5. Escores dos participantes nos fatores de instrumentalidade $(n=218)$

\begin{tabular}{lccccrr}
\hline \multicolumn{1}{c}{ Fatores } & Média & \multicolumn{2}{c}{$\begin{array}{c}\text { Desvio- } \\
\text { padrão }\end{array}$} & Frequência de participantes por intervalos \\
\cline { 5 - 7 } & & & $\mathrm{x} \leq 1$ & $1<\mathrm{x} \leq 2$ & $2<\mathrm{x} \leq 3$ & $\mathrm{x}>3$ \\
\hline FI1 - Envolvimento & 3,32 & 0,49 & 0,0 & 1,4 & 18,3 & 80,3 \\
FI2 - Justiça no Trabalho & 1,67 & 0,65 & 16,5 & 53,7 & 28,4 & 1,4 \\
FI3 - Desgaste e Desumanização & 2,37 & 0,73 & 2,8 & 27,1 & 52,3 & 17,9 \\
FI4 - Reconhecimento e & 2,87 & 0,65 & 0,5 & 11,0 & 43,1 & 45,4 \\
Independência Econômica & & & & & &
\end{tabular}

ANOVA $\quad F=518,30$ para $p<0,001$

No (Fl2) Fator Justiça no Trabalho, também ocorre dispersão. Porém, de modo inverso ao do fator (FI4) Desgaste e Desumanização. A soma das frequências dos intervalos moderado inferior $(1<x 2)$ evidencia que os profissionais de saúde percebem uma contribuição fraca do esforço no trabalho pera a obtenção de Justiça no Trabalho.

Observa-se, na Tabela 5, que os profissionais de saúde apresentam médias com magnitudes diferentes entre os fatores, o que é corroborado pela ANOVA ( $F=518,30$ para $p<0,001)$. E o teste post hoc (Bonferroni) revelou quatro níveis distintos de instrumentalidade, conforme se pode visualizar na Figura 2.

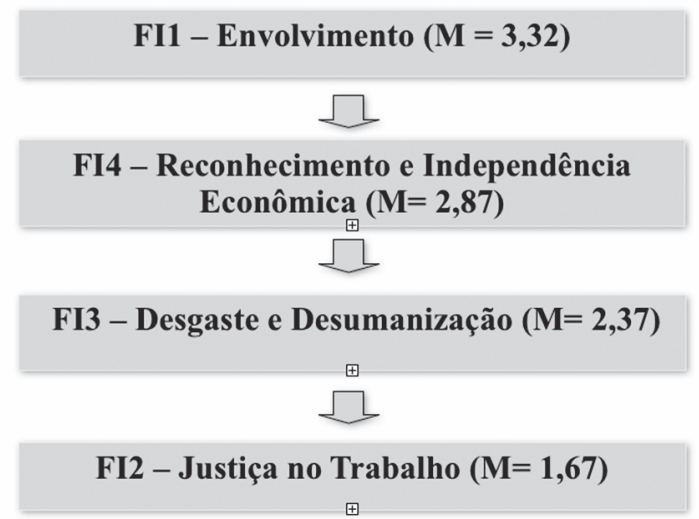

Figura 2. Níveis Identificados nos Fatores de Instrumentalidade

Conforme representado na Figura 2, os profissionais de saúde percebem o seu desempenho no trabalho nas UBS como mais útil para, dentre outros resultados, resolverem problemas, serem responsáveis pelas decisões, merecedores de confiança, incluídos no grupo e serem produtivos e eficientes (itens de Envolvimento); em seguida, para obtenção de reconhecimento e independência econômica; depois, para obtenção de desgaste e desumanização; e, por último, para obter justiça no trabalho.

Tendo em vista o segundo objetivo específico, estimou-se a força motivacional dos profissionais de saúde das UBS por meio do produto dos somatórios nos escores de expectativas e o somatório dos escores nos fatores de instrumentalidade, subtraído o produto dos escores no fator de expectativa e de instrumentalidade referidos a resultados do trabalho não atrativos, ou seja, para os quais se atribui, por hipótese, valência negativa. Para tanto, utilizou-se a seguinte 
fórmula: $\mathrm{FM}=\left[\sum(\mathrm{Fe} 1, \mathrm{Fe} 3, \mathrm{Fe} 4, \mathrm{Fe} 5) * \sum(\mathrm{Fi} 1, \mathrm{Fi} 2, \mathrm{Fi} 4, \mathrm{Fi} 5)\right]-(\mathrm{Fe} 2 * \mathrm{Fi} 3)$. Nela, está incluída valência negativa apenas aos escores nos fatores referentes ao Desgaste e Desumanização.

Como a aplicação da fórmula gera um resultado que, por hipótese, varia de 0 a 144, a força motivacional mínima encontrada entre os profissionais de saúde das UBS foi de 17,14 e a máxima, de 127,89. A média ficou em 76,62 e o desvio-padrão em 20,66. Subdividiram-se os escores em intervalos, a saber: os escores menores que 40 foram denominados de Força Motivacional Inferior; entre 40 até 73 de Força Motivacional Moderada Inferior; entre 73 a 106 de Força Motivacional Moderada Superior; e maiores que 106 de Força Motivacional Superior (Figura 3).

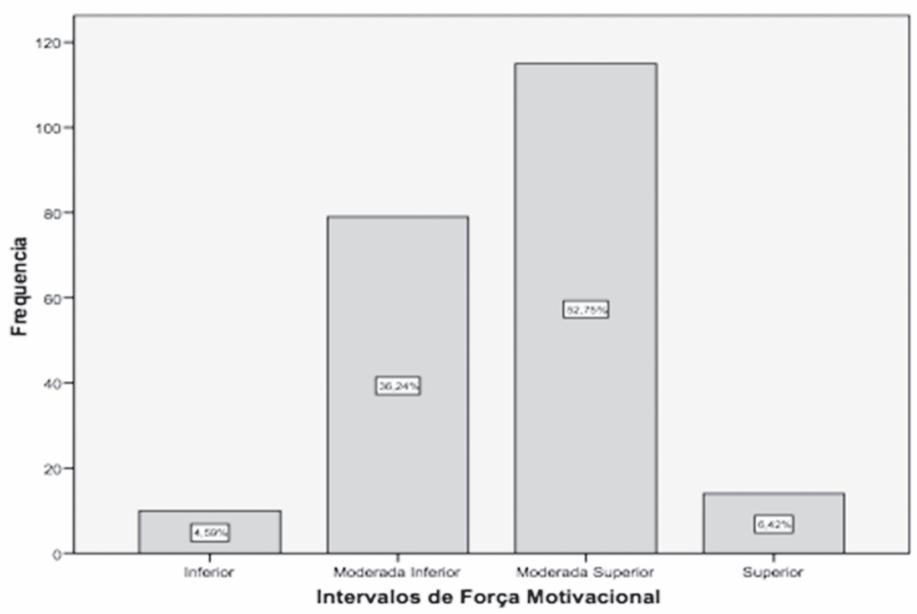

Figura 3. Gráfico da Distribuição da Força Motivacional

Como mostra a Figura 3, a maior concentração de profissionais de saúde $(52,8 \%)$ se encontra no intervalo de Força Motivacional Moderada Superior, seguida do intervalo de Força Motivacional Moderada Inferior (concentração de 36,2\%). Mas, apesar da distinção entre os intervalos moderado inferior e superior, observa-se que $89 \%$ da amostra apresentam força motivacional moderada. Porém, mesmo em menores concentrações, há profissionais no intervalo de força motivacional inferior $(4,6 \%)$ e no intervalo de força motivacional superior $(6,4 \%)$. Em outras palavras, há uma pequena quantidade de pessoas muito desmotivadas e outra, muito motivada.

O último objetivo específico deste artigo é mostrar a evolução da motivação para o trabalho dos profissionais de saúde, com o passar do tempo. Compararam-se, então, os resultados atuais com os encontrados nos estudos desenvolvidos por Borges e Alves-Filho (2001, 2003), com profissionais de saúde em Natal. Conforme mostra a Tabela 6, as expectativas dos profissionais de saúde permaneceram semelhantes, pois, apesar de os fatores não serem exatamente iguais, por equivalência, as médias foram muito próximas.

Por um lado, os fatores de expectativas - Autoexpressão e Justiça no Trabalho, Segurança e Dignidade e Responsabilidade - continuam, no tempo decorrido, contribuindo para manter a força motivacional dos profissionais de saúde. Por outro, o fator Desgaste e Desumanização contribui para baixar a força motivacional, sendo que sua média aumentou em 2003, permanecendo praticamente a mesma no último estudo (2008). 
Tabela 6. Fatores de expectativa e instrumentalidade em três Momentos

FATORES DE EXPECTATIVAS

\begin{tabular}{|c|c|c|}
\hline 2001 & 2003 & 2008 \\
\hline $\begin{array}{l}\text { Justiça no Trabalho e } \\
\text { Autoexpressão } \\
\text { M = 3,43 }\end{array}$ & $\begin{array}{l}\text { Justiça no Trabalho e } \\
\text { Autoexpressão } \\
M=3,56\end{array}$ & $\begin{array}{l}\text { Autoexpressão e Justiça no } \\
\text { Trabalho } \\
M=3,52\end{array}$ \\
\hline $\begin{array}{l}\text { Bem-estar e Independência } \\
\qquad M=3,41\end{array}$ & $\begin{array}{l}\text { Segurança e Dignidade } \\
\qquad M=3,47\end{array}$ & $\begin{array}{l}\text { Segurança e Dignidade } \\
\qquad M=3,50\end{array}$ \\
\hline $\begin{array}{l}\text { Responsabilidade } \\
\qquad M=3,40\end{array}$ & $\begin{array}{l}\text { Responsabilidade } \\
\qquad M=3,30\end{array}$ & $\begin{array}{l}\text { Responsabilidade } \\
\qquad M=3,34\end{array}$ \\
\hline $\begin{array}{l}\text { Desgaste e Desumanização } \\
\qquad M=1,88\end{array}$ & $\begin{array}{l}\text { Desgaste e Desumanização } \\
\qquad M=2,11\end{array}$ & $\begin{array}{l}\text { Desgaste e Desumanização } \\
\qquad M=2,10\end{array}$ \\
\hline \multicolumn{3}{|c|}{ FATORES DE INSTRUMENTALIDADE } \\
\hline 2001 & 2003 & 2008 \\
\hline $\begin{array}{l}\text { Envolvimento } \\
\qquad M=3,24\end{array}$ & $\begin{array}{l}\text { Envolvimento } \\
\qquad M=3,32\end{array}$ & $\begin{array}{l}\text { Envolvimento } \\
M=3,32\end{array}$ \\
\hline $\begin{array}{l}\text { Independência e } \\
\text { Bem-estar } \\
M=2,88\end{array}$ & $\begin{array}{c}\text { Reconhecimento e } \\
\text { Independência Econômica } \\
\qquad M=3,07\end{array}$ & $\begin{array}{c}\text { Reconhecimento e } \\
\text { Independência Econômica } \\
\qquad M=2,87\end{array}$ \\
\hline $\begin{array}{l}\text { Justiça no Trabalho } \\
\qquad M=2,39\end{array}$ & $\begin{array}{l}\text { Justiça no Trabalho } \\
\qquad M=3,29\end{array}$ & $\begin{array}{l}\text { Justiça no Trabalho } \\
\qquad M=1,67\end{array}$ \\
\hline $\begin{array}{l}\text { Desgaste e Desumanização } \\
\qquad M=2,35\end{array}$ & $\begin{array}{l}\text { Desgaste e Desumanização } \\
\qquad M=2,22\end{array}$ & $\begin{array}{l}\text { Desgaste e Desumanização } \\
\qquad M=2,37\end{array}$ \\
\hline
\end{tabular}

Sobre instrumentalidade, chama a atenção a queda no escore do fator Justiça no Trabalho, revelando a percepção dos profissionais de saúde de que o seu desempenho cada vez menos contribui para a obtenção do conjunto de resultados que compõem esse fator. Esse resultado ganha em importância quando nos reportamos ao fato de que Justiça no Trabalho vem se mantendo como um fator com maiores escores entre as expectativas. Em outras palavras, os profissionais de saúde têm elevadas expectativas nos resultados referentes à Justiça no Trabalho, porém a instrumentalidade do trabalho para obtenção desses resultados tem sido cada vez menor.

Com relação à força motivacional, no estudo realizado por Borges e Alves-Filho (2003) com profissionais de saúde em Natal, encontrou-se uma média de força motivacional de 85,34, com um desvio-padrão de 22,97. Comparando-se essa média com a encontrada no estudo atual, verifica-se que, no espaço de tempo decorrido entre esses dois estudos, houve uma queda do coeficiente, uma vez que, aplicado o teste $t$, a diferença entre as duas médias mostrou-se estatisticamente significativa ( $t=4,41$ para $\mathrm{p}<0,001)$.

Com relação à distribuição da força motivacional por intervalos (Figura 4), observou-se um aumento de profissionais no intervalo de força motivacional inferior (de 40 a 73). Em 2001, o percentual era de 1,6\%, em 2003, subiu para 2,8\% e, no atual estudo, esse valor praticamente dobrou (4,59\%). No outro extremo, diminuiu o número de participantes no intervalo de força motivacional superior (acima de 106). Em 2001, o percentual era de 20,40\% e de 2003 para 
2008, o número de profissionais nesse intervalo caiu consideravelmente (18,3\% para 4,6\%). Ou seja, $13,7 \%$ dos profissionais que apresentavam força motivacional superior passaram a se distribuir nos demais intervalos - nos de força motivacional moderada inferior (de 40 a 73) e moderada superior (de 73 a 106) - os quais subiram no atual estudo, como no de força moderada inferior, que também teve um considerável aumento, conforme mencionado. Esses resultados reafirmam o processo de desmotivação que está ocorrendo nas UBS com o passar do tempo, que se caracteriza pelo contraste entre esperar oportunidades de Autoexpressão e Justiça no Trabalho, e avaliar que, cada vez menos, está sendo possível obtê-las pelo desempenho.

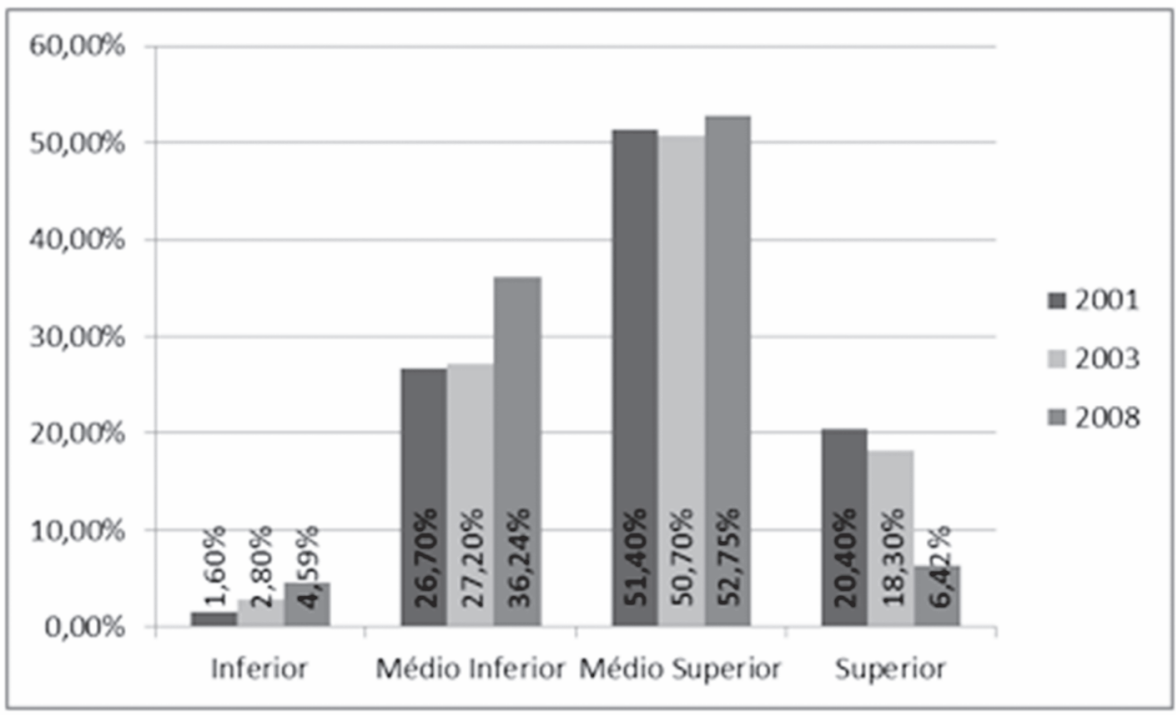

Figura 4. Evolução da força motivacional

\section{Discussão}

Os resultados apresentados revelam que a motivação para o trabalho, analisada à luz da Teoria da Expectativa de Vroom, que tem caráter processual, deve ser vista como um fenômeno que muda com o passar do tempo e em conformidade não somente com as características individuais, mas, também, com o contexto que as influencia. Esse foi o caso do contexto de saúde das UBS em Natal, conforme se buscou evidenciar. Além disso, estando a força motivacional em função das valências, expectativas e instrumentalidades que os trabalhadores atribuem aos resultados do seu trabalho, de acordo com a proposição de Vroom (1964), tais atribuições variaram acompanhando o contexto profissional dos participantes, corroborando os estudos de Hammond et al. (2011), Hertel, Konrad e Orlikowski (2004), Klein (1990) e Smrt e Karau (2011).

Com relação ao fator Justiça no Trabalho, os resultados significam que os profissionais de saúde percebem o seu esforço no trabalho como pouco responsável por sua obtenção, apesar de ser um fator com alta valência e expectativa, tanto no estudo atual como nos anteriores (2001 e 2003). E ao se comparar os resultados nesses tempos, observou-se que Justiça no Trabalho vem cada vez menos sendo percebidos como alcançada pelo desempenho, o que contribui negativamente para a motivação. Também contribuindo de forma negativa, porém de modo inverso, 
tem-se o fator Desgaste e Desumanização, cujas análises indicaram que apesar da valência negativa e baixa expectativa, os profissionais de saúde percebem seu trabalho como responsável por sua obtenção. Isso leva à conclusão de que o ambiente organizacional das UBS está contribuindo de forma negativa para a motivação dos profissionais que nele vivenciam o seu trabalho, podendo, assim, ser visto com antecedente da motivação, conforme expõem Johnson e Wallace (2011). Esses resultados refletem, portanto, o quadro descrito introdutoriamente sobre o sistema de saúde em Natal. A obtenção de Desgate e Desumanização no desempenho profissional provavelmente está associada a problemas como distribuição inadequada dos servidores, carência de mecanismos de avaliação de desempenho, discrepâncias salariais entre outros.

Em referência à força motivacional, comparando-se o atual resultado com os obtidos nos estudos anteriores, observa-se uma queda nessa força, que traduz a percepção dos profissionais de saúde de um contexto em degradação, o qual se revela na avaliação que fazem da falta de materiais, de equipamentos, de profissionais, de capacitação, de equidade, na falta de plano de carreira, cargos e salários justo e adequado, dentre outros. Traduz também a ingerência das políticas que são/estão postas, relacionadas a esses e outros aspectos referentes à gestão de recursos humanos do SUS. Tudo isso caracteriza um processo contínuo de degradação, revelada pela diminuição dos escores da força motivacional.

Finalmente, todos os resultados aqui mostrados e analisados, em uma perspectiva transversal do tempo e considerando mais de um nível de análise como uma tendência nesse campo de estudo, levam a cabo o que foi assinalado por Fernet (2013), quando se refere a importância de compreender o dinamismo do processo motivação em uma perspectiva temporal. Assim entendidos, os resultados do presente estudo contribuem teoricamente com o campo de estudo da motivação, em específico, com o uso da Teoria das Expectativas para a compreensão desse fenômeno, ao comprovar o amparo empírico desta. Outra contribuição deste estudo, entendido como um ponto forte, é que os resultados revelaram esforços que os profissionais de saúde, especificamente os das UBS, vêm fazendo no sentido de manterem-se motivados para um trabalho desenvolvido, ao longo do tempo, em condições materiais e sociogerenciais adversas, com mais perspectivas à deterioração, contrariando projetos, programas e propagandas que defendem o contrário.

Porém, não se pode deixar de evidenciar as limitações deste estudo, que dizem respeito não apenas ao tamanho da amostra final obtida após tabulação do IMST e a exclusão de categorias profissionais, mas pela dificuldade de caracterizar a população do estudo, o que termina por prejudicar o poder de generalização dos resultados, embora não os invalidando. De todo modo, considera-se a importância prática dos resultados, pois, deles, poderão se beneficiar primeiramente a SMS, em especial o setor de Gestão do Trabalho. Por consequência, os resultados são úteis aos diretores das UBS, aos sindicatos e aos profissionais de saúde como um todo. Além disso, os resultados podem também ser utilizados por psicólogos do trabalho e das organizações em suas práticas profissionais.

Por fim, deixa-se como sugestão para agenda de pesquisa, nova avaliação da motivação dos profissionais de saúde, uma vez que se passaram quase cinco anos desde a aplicação dos questionários em 2008, principalmente pelo fato de se poder considerar outro contexto socioinstitucional. 


\section{Antônio Alves Filho}

Doutor em Psicologia pela Universidade Federal do Rio Grande do Norte, Natal - RN. Brasil. Docente da Universidade Federal do Rio Grande do Norte, Natal - RN. Brasil.

E-mail: antonioalvesfil@gmail.com

\section{Livia de Oliveira Borges}

Doutora em Psicologia pela Universidade de Brasília, Brasília - DF. Brasil. Docente da Universidade Federal de Minas Gerais, Belo Horizonte - MG. Brasil E-mail: liviadeoliveira@gmail.com

\section{Endereço para envio de correspondência:}

Universidade Federal do Rio Grande do Norte, Campus Universitário, Lagoa Nova, 59072-970, Natal - RN, Brasil. Prédio do Centro de Ciências Sociais Aplicadas, sala do Departamento de Administração."

Recebido 11/06/2013, Aprovado 12/12/2013. 
Alves-Filho, A., \& Araújo, M. A. D. (2000). Um estudo da força motivacional dos funcionários do Banco do Brasil à luz da teoria da expectativa. In Associação Nacional dos Programas de Pós-Graduação em Administração (Org.). XXIV Encontro da ANPAD (Formato CDROM), Florianópolis: Autor.

Antoni, C. H. (2004). Research note: a motivacional perspective on change process and outcomes. European Journal of Work and Organizational Psychology, 13(2), 197-216.

Baum, J. R., \& Locke, E. (2004). The relationship of entrepreneurial traits, skill, and motivation do subsequent venture growth. Journal of applied Psychology, 89(4), 587-598.

Borges, L. O. (1997). Os atributos e a medida do significado do trabalho. Psicologia: Teoria e Pesquisa, 13, 211-20.

Borges, L. O. (1999). A estrutura fatorial dos atributos valorativos e descritivos do Trabalho: um estudo empírico de aperfeiçoamento e validação de um questionário. Estudos de Psicologia, 1, 107-158.

Borges, L. O., \& Alves-Filho, A. (2001). A mensuração da motivação e do significado do trabalho. Estudos de Psicologia, 6, 177-194.

Borges, L. O., \& Alves-Filho (2003). A estrutura fatorial do Inventário do Significado e Motivação para o Trabalho. Revista de Avaliação Psicológica, 2, 123-145.

Borges, L. O., Alves-Filho, A., \& Tamayo, A. (2008). Motivação e Significado do Trabalho. In M. M. M. Siqueira (Org.), Medidas do Comportamento Organizacional: ferramentas de diagnóstico e gestão (pp. 215-248). Porto: alegre: Artmed.

Borges, L. O., Tamayo, A., \& Alves-Filho, A. (2005). Significado do trabalho entre profissionais de saúde. In L. O. Borges (Org.), Os profissionais de saúde e seu trabalho (pp. 143198). São Paulo: Casa do Psicólogo.

Botazzo, C. (1999). Unidade básica de saúde: a porta do sistema revisitada. São Paulo: EDUSC.

Carvalho, V. D., \& Souza W. J. (2007). Pobres no ter, ricos no ser: trabalho voluntário e motivação na Pastoral da Criança. Revista de Administração Contemporânea, 11(2),113-134.
De Deu, C., Nijstad, B. A., Bechtold, M. N., \& Baas, M. (2011). Group creativity and innovation: a motivated information processing perspective. Psychology of Aesthetics, Creativity, and the Arts, 5(1), 81-89.

Dimenstein, M., \& Santos, Y. F. (2005). Avaliação em serviços de saúde: o que pensam usuárias da rede básica de Natal. In L. O. Borges (Org.), Os profissionais de saúde e seu trabalho (pp. 69-90). São Paulo: Casa do Psicólogo.

Erez, A., \& Isen, A. M. (2002). The influence of positive affect on the componnets of expectancy motivation. Journal of Applied Psychology, 87(6), 1055-1067.

Fernet, C. (2013). The Role of Work Motivation in Psychological Health. Canandian Psychology, 54(1), 72-74.

Francès, R. (1995). Motivation et efficience au travail. Liège: Mardaga.

Gondim, S. M. G., \& Silva, N. (2004). Motivação no trabalho. In J. C. Zanelli, J. E. Borges-Andrade \& A. V. B. Bastos (Orgs.), Psicologia, Organizações e Trabalho no Brasil (pp. 145176). Porto Alegre: Artmed.

Hammond, M. M., Neff, N. L. Farr, J. L., Schwall, A. R., \& Zhao, X. (2011). Predictors of Individual-Level Innovation at Work: A Meta-Analysis. Psychology of Aesthetics, Creativity, and the Arts, 5(1), 90-105.

Hangström, T., \& Gramerale, F. (1995). Young people's work motivation and value orientation. Journal of Adolescence, 18, 475-490.

Hertel, G., Konradt, U., \& Orlikowski, B. (2004). Managing distance by interdependence: goal setting, task interdependence, and team-baser rewards virtual teams. European Journal of Work and Organizational Psychology, 13(1), p. 1-28.

Houkes, I., Janssen, P. P. M., Jonge, J., \& Nijhuis, F. J. N. (2001). Specific relationships between work characteristics and intrinsic work motivation, burnout and turnover intention: A multi-sample analysis. European Journal of Work and Organizational Psychology, 10(1), p. 1-23.

Johnson, P., \& Wallace, C. (2011). Increasing individual and team performance in an organizational setiing towards the situational adaptation of regulatory focus. Consulting Psychology Journal: Practice and Research, 63(3), 190-201. 
Kanfer, R., \& Ackerman, P. L. (1989). Motivation and cognitive abilities: an integrative/aptitude-treatment interaction approach to skill acquisition. Journal of Applied Psychology, 74(4), 657-690.

Klein, J. I. (1990). Feasibility theory: a resource-munificience model of work motivation and behavior. Academy of Management Review, 15, 646-65.

Klein, H., Wesson, M., Hollenbeck, J., \& Alge, B. (1990). Goal commitment and the goal-setting process: Conceptual clarification and empirical synthesis. Journal of Applied Psychology, 84(6), 885 - 896.

Kolman, L., Chýlová, H., \& Selby, R. (2012). An attempt on new systematization of work motivation theories. Journal of Efficiency and Responsibilty in Education and Science, 5(2), 92-98.

Korman, A. K., Greenhaus, J. H., \& Badin, I. J. (1977). Personnel attitudes and motivation. Annual Review of Psychology, 28, 175-196.

Latham, G. P., \& Pinder, C. C. (2005). Work motivation theory and research at the dawn of the twenty-first century. Annual Review of Psychology, 56, 485-516.

Locke, E. A., \& Latham, P. G. (1990). Work motivation and satisfaction: light at the end of the tunnel. Psychological Science, 1(4), 240-246.

Locke, E. A., \& Latham, P. G. (2002). Building a practically useful theory of goal setting and task motivation. American Psychologist, 57(9), 705-717.

Massud, S. G. (2001). Análise da política de gestão da atenção básica de saúde no município de Natal - RN. Monografia, Departamento de Saúde Coletiva, Universidade Federal do Rio Grande do Norte, Natal.

Muchinsky, P. M. (1994). Psicologia Aplicada al Trabajo: una Introduccion a la Psicología Industrial y Organizacional. Bilbao: Desclée de Brouwer.

Nuttin, J. (1983). Teoria da motivação humana. (P. L. Cabra, Trad.). São Paulo: Edições Loyola. (Originalmente publicado em 1980).

Pérez-Ramos, J. (1990). Motivação no trabalho: abordagens teóricas. Psicologia USP, 1(2), 127-140.

Pearsall, M. J., Christian, M. S., \& Ellis, A. P. J. (2010). Motivating interdependent teams; individual rewards, shared rewards, or something in between? Journal of Applied Psychology, 95(1), 183-191.
Prieto (Orgs.), Tratado de Psicologia del Trabajo (pp. 215250). Madrid: Sintesis.

Régis, H. P., \& Calado, S. M. R. (2001). A teoria da expectância em um modelo de escolha do tipo Within-subject: um teste empírico da sua validade para a cultura brasileira [CD-ROM] In ENANPAD - Encontro Nacional dos Programas de Pós-Graduação em Administração. Rio de Janeiro: Autor.

Robbins, S. P. (2005). Comportamento Organizacional. 11aㅡ edição. São Paulo: Pearson. Prentice Hall, 2005

Salanova, M., Hontangas, P. M., \& Peiró, J. M. (2002). Motivación laboral. In J. M. Peiró \& F.

Sampaio, J. (2010). Resgate da teoria de motivação de Joseph Nuttin. Memoradum, 18, 84 94. Recuperado em 30 de maio de 2013, da World Wide Web: http://www.fafich.ufmg.br/ memorandum la18/sampaio01.pdf.

Secretaria Municipal de Saúde de Natal - SMS. (2003). Relatório de gestão 2003. Natal, RN.

Secretaria Municipal de Saúde de Natal - SMS. (2007). Relatório de gestão 2007. Natal: Autor.

Secretaria Municipal de Saúde de Natal - SMS. (2010). Relatório de gestão 2009. Natal: Autor.

Secretaria Municipal de Saúde de Natal. - SMS (2011). Relatório de gestão 2010. Natal: Autor.

Siqueira, M. M. M. (Org.), (2008). Medidas do comportamento organizacional: ferramentas de diagnóstico e de gestão. Porto Alegre: ARTMED.

Smrt, D. L., \& Karau, S. J. (2011). Protestant work ethic moderates social loafing. Group Dynamics: Theory, Research, and Practice, 15(3), 267-274.

Tamayo, Á., \& Paschoal, T. (2003) A relação da motivação para o trabalho com as metas do trabalhador. Revista de Administração Contemporânea, 7(4), 33-53.

Vroom, V. H. (1964). Work and motivation. New York: Wiley. 